\title{
Opinion and personal observation about how bad applying the knowledge in fragile counties may kill the patients?
}

\begin{abstract}
Patient were dying because of decision according to paper was published outside the country instated of believing in observations and practice where there was no any shortage in the qualifications or manpower.
\end{abstract}

Volume 8 Issue I - 2017

Abdulkafi Alsaied
Anaesthesia and Intensive Care Diploma, Qatar

Correspondence: Abdulkafi Alsaied, Anaesthesia and Intensive Care Diploma, Arab Board Residency Training Program in Anaesthesia and intensive care, Fellowship in Pain Management, Quality of Life Research Project Manager, Doha/ Qatar, P O Box: 19220,Tel 00974556995 I I,Email aalsaied@hamad.qa

Received: May 13, 2017 | Published: May 15, 2017

\section{Introduction}

I was working as anesthesiologist, intensivist and pain management. During the period of 2011. When I was serving in emergency department for resuscitation and Airway management as the main personal in charge for Airway assessment and management.

\section{The circumstances of the cases}

A new head for ambulance service was recruited newly to Ambulatory services in our medical corporation and depending on two newly published articles concluded that the outcome of COMBI tube is better than ENDOTRACHEAL tube in cases of prehospital airway management, and accordingly he decided to prevent a highly qualified anesthesia technicians whom were doing Endotracheal intubations for many years from putting endotracheal tube and substitute it by introducing COMBI tube blindly.

I was astonished when unordinary I had received three cases within 10days were arrived the emergency department in the Main Hospital by Ambulance Team with failure of resuscitation. I knew The technicians very well how much they are highly qualified and efficient to perform perfect endotracheal intubation as they usually do, I asked them if it was difficult for intubation; and according to my witness looks to be easy but they said NO it was not ?! And we know it is very easy for us to do but we had received a new order from our head of department to not do any endotracheal intubation outside hospital and now we have only the privilege to do the COMBI tube according to the new decision.

I could not believe how much it was painful to me so I went ahead to the head of the AMBULANCE department and discussed the issue with him. He refuse the discussion and asked me to read the articles.

I went to the chairman of my department (Anesthesia and Intensive care department) and I told him my observations, also he refuse to response and ask me to do research opposite that finding; sounds looks good but there are people dying. He asked me to follow the order in emergency department as it.

According to the policies was followed by the corporation it was very difficult to start a study; they build very complicated policies even for case study because the put the following difficulties: a. Very complicated format

b. Very hard conditions

c. Very long procedures

\section{The documented knowledge}

a. I found a lot of studies regarding the use of supra glottis airway instruments instead of endotracheal tube.

b. Some of them done on manikins and others were performed on patients but they did not document the weight and the situation of the abdomens.

\section{Why this documented knowledge did not work in these cases}

From my observation I can enumerate the following reasons for the failure:

A. The patients were obese and have large bellies.

B. They have full stomach.

C. The coarse movement during transportation prevent the stabilities of COMBI Tube.

D. Continuous chest compression dislodging the COMBI tube from it's please especially with obese, large abdomen or fully stomach.

\section{The result}

Patient were dying because of decision according to paper was published outside the country instated of believing in observations and practice where there was no any shortage in the qualifications or manpower.

The head of the Ambulance continue and even he did not studied the cases. Also the head of the Anesthesia and intensive care did the same.

\section{Conclusion}

I write her my wetness from my observation during my practice; which still making me fell pain, so I wanted to say that there are a 
lot of places in the advanced country or whom had a good facilities to do everything but still killing patients by knowledge instead of by ignorance.

\section{Acknowledgements}

None.

\section{Conflicts of interest}

Author declares there are no conflicts of interest.

\section{Funding}

None. 